\title{
CHARACTERISTICS OF PIPE BREAKWATERS
}

hikal e.m, Koraim A. S

\begin{abstract}
The wave transmission behind closely spaced pile breakwaters consisted of one or two rows of vertical square or circular piles was examined experimentally. Intermediate and shallow water waves were used. Different parameters are tested such as, the gap-diameter ratio, the relative space between the rows of piles, the wave length, and the arrangement of the piles (straight or staggered). The proposed breakwater efficiency as a function of the wave transmission was measured at different locations along the wave flume. A simple empirical formula for estimating the wave transmission coefficient was suggested. The square pile breakwater was found to be more efficient than the circular piles. Also, it is concluded that the efficiency of the two types of pile breakwaters increases as the relative gap distance between piles decreases and as the relative span between pile rows increases. Finally, the effect of the pile arrangements (straight or staggered) are slightly affect the wave transmission
\end{abstract}

